\title{
El diagnóstico de la muerte encefálica en Latinoamérica
}

\section{The diagnosis of brain death in Latin America}

\author{
R. Matesanz
}

Organización Nacional de Trasplantes, España

Recibido el 16 de julio de 2009; aceptado el 16 de julio de 2009

Disponible en Internet el 3 de octubre de 2009

\section{El diagnóstico de la muerte encefálica en Latinoamérica}

Los trasplantes de órganos, uno de los paradigmas de la moderna medicina, serían simplemente imposibles sin el reconocimiento de que la muerte encefálica equivale desde un punto de vista científico, ético y legal a la muerte del individuo. Salvo el trasplante de paciente vivo — restringido al riñón y en mucha menor medida al hígado- y las donaciones en asistolia -apenas un 5\% en España e inexistentes en muchos países ${ }^{1}$ - , la obtención de órganos para trasplante sólo es posible por la existencia del concepto de muerte encefálica.

Este hecho, que en principio debería ser una obviedad, medio siglo después de su reconocimiento científico ${ }^{2}$ de hecho supone que en la mayor parte del mundo, y desde luego en nuestro medio, la donación de órganos se restrinja al ámbito de las unidades de cuidados intensivos y quede mayoritariamente en manos de los intensivistas. Cualquier estrategia organizativa que no pase por el reconocimiento de esta situación está llamada al fracaso y, efectivamente, en el plano internacional hay numerosos ejemplos de lo que estoy diciendo.

El modelo español de donación y trasplantes es universalmente reconocido como el más eficaz para el desarrollo de un sistema de donación ${ }^{1,3}$. La filosofía que lo inspiró desde el primer momento es un sistema centrado en la adecuada organización de todos los pasos necesarios para que se materialice la donación de órganos en los pacientes fallecidos

Correo electrónico: rmatesanz@msps.es en muerte encefálica. Los encargados de gestionar este proceso son mayoritariamente intensivistas. No podía ser de otra forma si tenemos en cuenta que toda la donación de órganos gira alrededor de un enfermo a quien hay que realizar el diagnóstico de muerte, mantener en buena situación hemodinámica, contactar con la familia, organizar todo el proceso de extracción y trasplante de órganos, etc. Son tareas para las que los especialistas en medicina intensiva están perfectamente situados, bien por su formación básica, bien mediante un entrenamiento específico mucho más sencillo de efectuar que con cualquier otro médico.

Por esto, a principios de 2009, de los 224 médicos que ejercían como coordinadores de trasplantes en los 167 hospitales españoles autorizados para la donación, nada menos que el $79 \%$ eran intensivistas ${ }^{4}$, un porcentaje que sigue creciendo año tras año. También por esto la Organización Nacional de Trasplantes (ONT) de España y la Sociedad Española de Medicina Intensiva, Crítica y Unidades Coronarias (SEMICYUC) establecieron hace ya 4 años un acuerdo por el que todos los residentes de intensivos en formación pueden recibir un curso específico sobre donación y trasplante, inevitablemente llamado a fortalecer esta relación entre donación y cuidados intensivos. En la misma línea, la reglamentación española sobre muerte encefálica y donación en asistolia ${ }^{5}$, probablemente una de las mejores y más modernas del mundo pese a tener ya una década, sólo fue posible gracias a un perfecto entendimiento y colaboración con todas las sociedades científicas lideradas por intensivistas que llevaban preparando su elaboración desde varios años antes ${ }^{6,7}$.

En definitiva, el modelo español de donación y trasplante ha demostrado a lo largo de los años la necesidad de unas 
reglas del juego perfectamente claras y unos protagonistas del proceso convencidos, motivados y bien entrenados. Todo eso tenemos en España y todo eso es necesario si queremos trasladar nuestra experiencia a otros países ${ }^{8}$.

\section{La cooperación con Latinoamérica}

La Red/Consejo Iberoamericano de Donación y Trasplantes (RCIDT) se crea en el año 2005, en el transcurso de la VIII Conferencia Iberoamericana de Ministros de Salud, celebrada en Granada. Está compuesta por 21 países: España, Portugal y todos los países americanos de habla española y portuguesa. Su objetivo es desarrollar la cooperación entre los países miembros en todos los aspectos relacionados con la donación y el trasplante de órganos, tejidos y células. Los países están representados por un profesional de los trasplantes o de los sistemas organizativos de donación, designado por sus respectivos Ministerios de Salud. La ONT ostenta, desde su creación, la Secretaría Permanente del Consejo y también la Presidencia de éste?.

En sus 4 años de funcionamiento, la RCIDT ha desarrollado una intensa actividad centrada sobre todo en la formación de profesionales mediante estancias en España y cursos especializados a ambos lados del Atlántico. De igual manera, la RCIDT ha elaborado un total de 10 recomendaciones y documentos de consenso acerca de temas muy básicos de la donación y el trasplante: cómo se deben estructurar las organizaciones de trasplantes, quién tiene que ser coordinador, qué perfil profesional debe tener y cómo se debe formar, cuáles son los principios éticos que deben presidir la donación y el trasplante, etc.

La RCIDT se está constituyendo en referente técnica, ética, formativa y de cooperación para el desarrollo de programas de trasplante en todos los países de la región, y su funcionamiento es, asimismo, modelo para la OMS en otras regiones del mundo. Se han creado, reestructurado o reavivado organizaciones de donación y trasplante en países que no contaban con éstas o cuya actividad era mínima o nula, dependientes de la autoridad sanitaria o con su apoyo, siguiendo el modelo español, y con la creación de redes de coordinación.

Se ha producido en los últimos años un aumento significativo en las tasas de donación de diversos países, como Argentina, Colombia, Cuba, República Dominicana, Venezuela y Uruguay. Se da el caso de que Uruguay fue ya en 2006 el tercer país del mundo en índice de donación, sólo por detrás de España y Estados Unidos.

Se trata en suma de una red que está cumpliendo con creces las expectativas despertadas en el momento de su creación, que ha conseguido ya resultados muy tangibles, pero que sobre todo ha logrado cohesionar profesionales y administraciones de muy diversos países y crear las bases para que Iberoamérica se posicione en pocos años en un lugar de privilegio en este campo de la sanidad de cada vez mayor importancia en el tratamiento de enfermedades de gran impacto y relevancia social.

Uno de los aspectos en los que más acuerdo ha habido sobre la necesidad de una armonización para establecer criterios diagnósticos homogéneos, actualizados y consensuados con las sociedades científicas de acuerdo a estándares internacionales es el de la muerte encefálica. El trabajo efectuado en este tema específico, liderado y desarrollado por la Dra. Dolores Escudero con su habitual brillantez y capacidad de trabajo, se plasma en 2 artículos que se publican en el presente número de Medicina Intensiva $^{10,11,12}$.

Llegar hasta aquí ha representado un esfuerzo enorme de armonización de 21 países, cada uno con una legislación diferente, en ocasiones bastante apartada de las corrientes actuales y además fácilmente influenciables por determinadas filosofías ultraconservadoras que, contra toda lógica y a contracorriente de la ciencia, aparecen de manera periódica como los Ojos del Guadiana. Para estos países es fundamental disponer de un respaldo internacional de la solvencia de la ONT y la RCIDT a la hora de desarrollar una nueva legislación, liquidar una polémica mediática o reforzar la práctica médica de sus profesionales en un tema tan importante como éste.

En definitiva, la labor que viene realizando el sistema español de donación y trasplantes, coordinado por la ONT, supera con mucho el ámbito de nuestras fronteras y se extiende por todo el mundo a través de la colaboración con la OMS y la Sociedad Internacional de Trasplantes. Es, sin embargo, Latinoamérica el lugar donde mejor se ejemplifica esta colaboración y liderazgo, como aquí se pone de manifiesto y, por mi parte, sólo queda agradecer a Medicina Intensiva la oportunidad de darlo a conocer.

\section{Bibliografía}

1. Rafael Matesanz, editor. El modelo español de donación y trasplantes. Madrid: Aula Médica; 2008.

2. Mollaret P, Goulon M. Le coma dépassé. Rev Neurol. 1959;101:3-15.

3. Matesanz R, Domínguez Gil B. Strategies to optimize deceased organ donation. Transplant Rev. 2007;21:177-88.

4. Organización Nacional de Trasplantes. Disponible en: URL: www.ont.es.

5. Real Decreto 2070/1999 de 30 de diciembre, por el que se regulan las actividades de obtención y utilización clínica de órganos humanos y la coordinación territorial en materia de donación y trasplante de órganos y tejidos. Boletín Oficial del Estado, N.o 3/2000 (Ener. 04, 2000) [citado May 2009]. Disponible en URL: http://www.rcidt.ont.es.

6. Sociedad Española de Neurología. Diagnóstico neurológico de la muerte cerebral. Dictamen Candanchú, 1993. Quadern Caps. 1994;20:45-6.

7. Escalante Cobo JL, Escudero Augusto D. Conclusiones de la III Conferencia de Consenso de la SEMICYUC. Muerte encefálica en las unidades de cuidados intensivos. Med Intensiva. 2000;24:193-7.

8. Matesanz R. Factors influencing the adaptation of the Spanish model of organ donation. Transplant International. 2003;16:736-41.

9. Matesanz R. Spanish cooperation with Latin America in transplant organization: The "ALIANZA" programme. Organs and Tissues. 2005;2:87-90.

10. Escudero D, Matesanz R, Soratti CA, Flores Jl. Red/Consejo Iberoamericano de Donación y Trasplantes. Muerte encefálica en Iberoamérica. Med Intensiva doi:10.1016/j.medin. 2009.07.011.

11. Matesanz R. Red/Consejo Iberoamericano de Donación y Trasplantes. Consideraciones generales sobre la muerte encefálica y recomendaciones sobre las decisiones clínicas tras su diagnóstico. Med Intensiva doi:10.1016/j.medin.2009.06.004.

12. Escudero D. Diagnóstico de muerte encefálica. Med Intensiva. 2009;33:185-95. 